\title{
CONCEPÇÕES DE LEITURA E LINGUAGEM: DIÁLOGOS COM BAKHTIN
}

\author{
Jacqueline de Fátima dos Santos Morais ${ }^{\mathrm{i}}$ \\ Jacqueline Martins da Silva ${ }^{\text {ii }}$
}

\begin{abstract}
Resumo: Este trabalho é um recorte de uma investigação de mestrado já finalizada. Após uma breve apresentação da pesquisa que originou este artigo, privilegiamos as discussões sobre concepções de linguagem e de leitura. Para isso, partimos das ideias de Bakhtin e enfocamos a linguagem como construção social, expressão viva de experiências, resultando de interações humanas. O texto traz ainda um diálogo com Paulo Freire, tanto no que se refere as suas reflexões sobre leitura como na discussão sobre formação docente. Defendemos a leitura como ato dialógico, como ato produzido na interação entre leitor/texto/auto. Por fim, defendemos a necessidade de ouvirmos as vozes de professores e professoras e levarmos em conta suas experiências na formulação de políticas e práticas formativas.
\end{abstract}

Palavras-chave: Linguagem. Leitura. Processo dialógico. Formação docente.

\section{CONCEPTIONS OF READING AND LANGUAGE: DIALOGUES WITH BAKHTIN}

This work is a cut from an already completed master's degree research. After a brief presentation of the research that originated this article, we privilege discussions about conceptions of language and reading. For this, we start from Bakhtin's ideas and focus on language as a social construction, a living expression of experiences, resulting from human interactions. The text also brings a dialogue with Paulo Freire, both in what concerns his reflections on reading and in the discussion about teacher education. We defend reading as a dialogic act, as an act produced in the interaction between reader / text / self. Finally, we defend the need to listen to the voices of teachers and take into account their experiences in the formulation of policies and training practices.

Keywords: Reading. Dialogic process. Teacher training.

\section{Introdução}

A palavra não é um objeto, mas um meio constantemente ativo, constantemente mutável de comunicação dialógica. Ela nunca basta a uma consciência, a uma voz (BAKHTIN).

Na pesquisa de mestrado que inspira este trabalho, investigamos histórias de leitura de cinco professoras que atuaram com formação continuada de professores da Fundação Municipal de Educação de Niterói- município do estado do Rio de Janeiro. Neste processo de pesquisa, buscamos os relatos orais enfocando o viés memorialístico. O objetivo se direcionava a 
compreender como as professoras/sujeitos da pesquisa constituíram ao longo de suas trajetórias, relações com a leitura dos chamados "textos literários".

Apesar de ser um conceito central na pesquisa a que nos referimos, não trataremos dessa temática aqui por fugir do foco temático deste artigo. Podemos, no entanto, afirmar que nossa preocupação esteve na dimensão discursiva da linguagem (BAKHTIN, 2011; 2014) e que esta opção nos levou à escolha da entrevista como instrumento metodológico. Entendemos entrevista como um espaço dialógico de entrefalas e contrapalavras e não como relação comunicativa que impõe a um o lócus de apenas perguntar, e a outro, o de somente responder. Se é verdade que na esfera social cada interlocutor ocupa certo lugar social no qual se estabelecem relações hierárquicas e certos usos e discursos, por outro esse lugar não é fixo. A entrevista, portanto, pode ser uma relação na qual se estabelece rupturas de hierarquias verticais. Pode ser um tempo de predomínio da conversa, e não de turnos de falas nos quais há uma pergunta, seguirá, invariavelmente, uma resposta que tentará ser clara e objetiva à questão. Assim, nos atrevemos a seguir menos os cânones do que seria uma entrevista formal, nos enveredando, apoiadas em Nilda Alves (2003) e Eduardo Coutinho (1997), no que estes discutem e vivem a respeito de conversa.

Além disso, buscamos analisar a força potencial presente nos discursos das entrevistadas, buscando perceber no encontro com as narrativas, a polissemia, a polifonia e os efeitos de sentido que nos provocavam. Deste modo, nos diz Bakhtin que "cada enunciação, cada ato de criação individual é único e não reiterável...” (BAKHTIN, 2014, p.79). As palavras deste autor nos levam a considerar as narrativas como atos únicos e irrepetíveis.

Afirmar a entrevista como gênero do discurso significa dizer com Bakhtin que ela é um tipo relativamente estável de enunciado, em processo de regularização a partir dos usos em interações concretas.

Sabemos que certos gêneros surgem, outros desaparecem, outros ainda se reconfiguram a partir da necessidade que apresentam novos modos de interlocução. Mesmo reconhecendo a "conversa" como uma possibilidade metodológica legítima, na investigação que circunscreve este texto, optamos por assumir a entrevista, pelo viés dialógico, como metodologia de pesquisa.

Nos debruçar sobre essa ideia nos parece potente e nos provoca levar em conta que:

ao falar, sempre levo em conta o fundo aperceptível da percepção do meu discurso pelo destinatário: até que ponto ele está a par da situação, dispõe de conhecimentos especiais de um dado campo de cultura da comunicação; levo em conta as suas concepções e convicções, os seus preconceitos (do meu ponto de vista), as suas simpatias e antipatias tudo isso irá determinar a ativa compreensão responsiva do meu enunciado por ele (BAKHTIN, 2011, p. 302). 
Por isso, a tessitura das narrativas produzidas nas entrevistas constitui uma dentre as muitas composições possíveis, dada a parcialidade no que tange ao modo como podemos percebê-las, nos relacionar com elas, entendendo com Bakhtin (2014) que "a compreensão é uma forma de diálogo; ela está para a enunciação assim como uma réplica está para a outra no diálogo. Compreender é opor a palavra do locutor uma contrapalavra." (BAKHTIN, 2014, p. 137). Dito de outro modo: na tessitura dialógica que buscamos estabelecer, a tentativa de compreensão pode se dar de diversas formas: concordando, refletindo; discordando, refratando.

Reconhecemos que uma série de fatores podem interferir e influenciar as respostas, não sendo estas, portanto, representativas de uma verdade absoluta, mas das verdades que formam a cada um. Afinal, como aborda Bakhtin (2011) as condições de produção dos discursos, os seus destinatários, o contexto das enunciações, podem determinar as palavras que são ditas no ato comunicativo, bem como seus significados.

Bakhtin (2011) também provoca-nos a perceber que as narrativas produzidas no presente, as que foram produzidas durante a pesquisa, não fogem a regra, podem estar infinitamente impregnadas de passado e futuro. Por isso, as histórias narradas no processo de investigação que vivemos não surgiram do vazio, não são produções isoladas e descontextualizadas, mas encontram-se ligadas a enunciados anteriores, bem como ao que poderá ser dito posteriormente. Nesse sentido, tecer as falas com o cuidado de quem manuseia uma preciosidade, suscetíveis ao que pode ter acontecido e ao que poderá vir a ocorrer, torna-se mais coerente do que somente referir-nos a elas.

Resgatar, por meio de relatos memorialísticos, histórias e experiências de leitura vividas ajuda-nos a compreender não só os múltiplos modos de formação, mas também de apropriação e interação com a leitura. Portanto, investigar o modo como certos sujeitos se relacionavam com a leitura, e no foco que tomamos na pesquisa que aqui trataremos, a leitura de textos literários, possibilita-nos refletir sobre a concepção de leitura como ato dialógico e linguagem, como prática social.

\section{Leitura e linguagem na pesquisa}


Com base na crítica de Walter Benjamin (1994) à modernidade e à ideia de progresso que resulta no definhamento da arte de narrar e intercambiar experiências, temos buscado, ao longo da pesquisa, conceber o sujeito como ser constitutivo de subjetividades e atravessado por uma multiplicidade de espaços/tempos formativos. Por isso, as narrativas ouvidas como parte da investigação que aqui trazemos, podem ser compreendidas como histórias construídas de modo singular, mas também coletivo. Bakthtin nos ajuda na elaboração do pensamento sobre o sujeito, o outro, pois podemos encontrar em seus escritos o outro como ser que se constitui nas relações. O outro que se constrói em interação e interlocução com outros. Isso possibilita-nos pensar responsivamente sobre o mundo, sobre a vida e sobre o que estamos sendo. (BAKHTIN, 2014). Nesse sentido, o indivíduo, como sujeito histórico, se constitui na/pela linguagem.

A linguagem para Bakhtin tem caráter dialógico e como criação coletiva está em movimento e inacabamento. A palavra "sempre carregada de um conteúdo ou de um sentido vivencial" (BAKHTIN, 2014, p. 99) encontra-se como arena onde os valores sociais podem ser explicitados e postos em confronto. A linguagem pode ainda ser compreendida, a partir de Bakhtin, como construção social, expressão viva de experiências vivas, que resulta da interação humana, nascendo de um diálogo entre o eu e outro.

Nesta via de discussão, uma pergunta parece peculiar: em que medida compreender a linguagem, pelo viés bakhtiniano, pode nos ajudar na relação com a leitura? Ora, se permitimonos entender a linguagem tal como Bakhtin propõe em seus estudos sobre a filosofia da linguagem, compreenderemos que o ato de ler não é mera decodificação de textos mas ato polifônico, composto pelas diversas vozes que orquestram os sentidos no texto.

Em consonância com as ideias de Bakhtin, Kramer (1993) defende que linguagem "é produção humana acontecida na história; produção que - constituída nas interações sociais, nos diálogos vivos - permite pensar as demais ações e a si própria, constituindo a consciência." (KRAMER, 1993, p. 103).

As reflexões de Kramer nos ajudam a compreender que pela linguagem os sujeitos penetram e produzem cultura. Nesse sentido, história e linguagem não acontecem isoladamente, mas se entretecem. A linguagem permite recriarmos significativamente as experiências do passado atribuindo a elas outros sentidos. Afinal, sentidos de outros tempos e lugares se fixam na palavra, pois esta tem franjas, como diz Bakhtin. Então, muitas são as vozes que falam em um processo dialógico.

No tocante às concepções de leitura, muitas estão em disputa tanto no campo teórico quanto na prática. As mudanças sócio-históricas contribuíram para que em todas as áreas do conhecimento 
acontecessem mudanças conceituais. No que diz respeito à leitura não foi diferente. Dependendo do contexto histórico, de vida, social e cultural, há diferentes entendimentos no que tange ao conceito de leitura. Essas diferenciações nos ajudam a entender como os processos de ensino da leitura vão se constituindo em dimensões polissêmicas.

No Novo Dicionário Aurélio da Língua Portuguesa (1986), por exemplo, encontramos a definição de leitura como: "ato ou efeito de ler". (p.1019). O dicionário mostra-nos uma definição rígida e cristalizada de leitura, como "palavra da língua neutra e não pertencente a ninguém." (BAKHTIN, 2011, p. 294). Os estudos bakhtinianos ajudam-nos a inferir que no dicionário encontramos as palavras conceituadas fora das situações comunicativas. Como se vê, ao consultar o dicionário deparamo-nos com um sentido estabilizado para o termo leitura, esvaziado dos sentidos subjetivos, das histórias e experiências que cada sujeito carrega.

Como podemos pensar, então? Para cada indivíduo há um contexto de vida e múltiplos processos de formação como leitor. Estes podem acontecer em meio à complexidade e tensões vividas, na multiplicidade dos espaços/tempos e na tessitura das relações. Para este tecer não há receita, muito menos linearidade nas trajetórias percorridas. Por isso, alguns podem relatar experiências de formação leitora onde o pano de fundo é o seio da família. Outros, que não perceberam a existência de uma figura incentivadora desse processo. Outros podem narrar a escola como lugar de encontro com a leitura. Outros, ainda, podem dizer que se formam leitores pela vida afora.

Neste sentido, pensar a leitura por um viés mais contextual e próximo das interações humanas pode ajudar-nos a compreender a leitura como um mergulho na própria existência e nas histórias que se entrelaçam ao vivido. Investigar os sentidos da leitura para certos sujeitos, nos ajuda a compreender os significados produzidos por cada um, dialeticamente, ao longo da vida.

Pensar em leitura nos convida a pensar para além do texto verbal impresso em papel. A leitura pode revelar-se ao leitor sob múltiplas linguagens: os matizes de cores numa árvore, o barulho das ondas do mar, uma fotografia, uma imagem, uma marca no corpo, um gesto ou uma expressão facial podem ser lidos e entendidos como texto. O clássico artigo "A importância do ato de ler" de Paulo Freire (2003) nos diz que não se leem apenas livros, lê-se o mundo. Lemos as expressões de alegria ou tristeza no rosto das pessoas, "o verde da manga-espada verde, o verde da manga-espada inchada, o amarelo-esverdeado da mesma manga amadurecendo, as pintas negras da manga mais além de madura.” (FREIRE, 2003, p. 13). A multiplicidade de textos possibilita-nos ricos relacionamentos com o mundo. 
Defendemos, portanto, a leitura como ato dialógico, como ato produzido na interação entre leitor/texto/autor, como encontro de alteridades (BAKHTIN, 2011). Tal concepção de leitura implica a ideia de entrelace dialógico, no qual os discursos são atravessados valores ideológicos, tensão e diferentes pontos de vista sobre o mundo. Ler pode promover desdobramentos de sentidos, além de desencadear no leitor uma "compreensão ativamente responsiva" (BAKHTIN, 2011, p. 272).

Portanto, ler pode ser compreendido, nesta perspectiva como ato comunicativo já que ler implica compreender ativa e responsivamente ao que lemos. Em outras palavras, produzimos, explicita ou implicitamente, uma resposta, concordância ou objeção ao que lemos.

Como essa forma de conceber a leitura pode nos ajudar a pensar as práticas de ensino da leitura na escola? Uma delas é pensarmos que ao ler o individuo o faz como um participante real da comunicação discursiva e não como um leitor passivo. Desta forma, nossos alunos, mesmo em fase inicial da aprendizagem da leitura, trazem significações externas para dentro do texto, produzindo, explicita ou implicitamente, uma resposta, concordância ou objeção ao que lê.

De acordo com Bakhtin (2014), a interpretação é "como correlacionamento com outros textos e a reapreciação em um novo contexto (no meu, no atual, no futuro)." (BAKHTIN, 2011, p. 401). Nesse sentido, só pode haver compreensão de um texto na interação, no diálogo do leitor com o texto, por isso não pode-se afirmar que haja somente uma leitura ou interpretação. Assim, os sentidos são construídos na interação do leitor com o texto. A multiplicidade das significações fundamenta-se no social, nos contextos e também no singular, na pessoal.

A leitura pelo viés dialógico também pode ser entendida como possibilidade de nos depararmos com o outro (BAKHTIN, 2014), no sentido bakhtiniano de entender o termo. Nessa perspectiva, a leitura não encontra-se nem no texto, nem fora dele, mas nas possibilidades de relação e interlocução entre aquele que escreve e aquele que lê, mediado pelo texto.

É interessante aqui lembrar que, etimologicamente, texto nos remete a ação de tecer fios produzindo tecidos a partir das relações entre eles. Texto, portanto, produz e é produzido por uma rede de sentidos. Para Bakhtin, texto não é uma coisa sem voz. Como ato humano, o texto é marcado por uma língua, o que o introduz no campo dos signos. O texto se realiza no cruzamento dos sujeitos discursivos, mobilizando sentidos que estes sujeitos criam no ato de produção ou leitura. Cada texto, portanto, nunca é repetição do mesmo.

Revistar os escritos de Freire (2003), além dos de Bakhtin, ajuda-nos na discussão aqui pautada que é a leitura como possibilidade de diálogos. Freire aponta que, a leitura pode se constituir como ato crítico e reflexivo, pois há um entrelaçamento entre a leitura e o contexto ao 
qual o sujeito pertence. Segundo o autor, a palavra pronunciada ou a leitura realizada flui do mundo, portanto, apropriar-se do texto surge indissociável da ideia de ler o mundo. Além disso, exercemos a leitura como ato crítico e reflexivo à medida que a entendemos como um movimento vivo em que apropriando-me, reflexivamente, do que é lido e mediante uma prática consciente, tenho a possibilidade de transformar e reescrever o meio no qual estou inserido.

Entendemos que essa concepção de leitura em Freire reflete um posicionamento político que se preocupa em contribuir para a democratização da sociedade. Há, a nosso ver, frente às reflexões que o leitor se propõe a fazer, compromisso com o coletivo, possibilidade de realizar escolhas conscientes, de pensar sobre as possíveis intervenções sociais que podem nascer e se fortalecer a partir da leitura. Essa leitura baseada na criticidade e reflexão pode promover a liberdade do leitor em fazer as suas escolhas, podendo desestabilizar, interiormente, o indivíduo; gerando-lhe dúvidas e anseios por mudanças, visto que o permite articular conhecimentos.

Trazer à cena a concepção freireana de leitura em que o leitor pode vivenciar inquietações, relacionando ideias e pensamentos a fim de promover reflexão sobre o assunto; para, finalmente, ter a prática consciente, que consiste no resultado desse novo sujeito transformado, mas não concluído já que muitas leituras de mundo serão feitas e refeitas, leva-nos a defesa da leitura como atividade permanente. Essa defesa pressupõe entender o ato de ler para além do cumprimento de uma finalidade ou como pretexto para realização de uma atividade.

Neste sentido a leitura de Freire e Bakhtin tem nos convidado a tecer uma boa conversa já que articular os dois autores não só é um exercício intelectual provocativo, como necessário em tempos como os que vivemos.

Tomando o texto “A importância do ato de ler", encontramos a sua tese principal: “a leitura do mundo precede a leitura da palavra" (FREIRE, 2003, p. 13).

Implicada a esta, encontramos a ideia de que leitor necessita desenvolver a compreensão crítica. Ler a palavra sem se interrogar sobre o mundo gera um ato de mera decodificação do escrito. Para Freire, desta forma, ler a palavra é ultrapassar a maneira despolitizada, acrítica e inconsciente de lidar com o mundo escrito.

Ler, portanto, envolve...

uma compreensão crítica do ato de ler, que não se esgota na decodificação pura da palavra escrita ou da linguagem escrita, mas que se antecipa e se alonga na inteligência do mundo (FREIRE, 2003, p. 11).

Encontramos no texto a ideia, também potente e inovadora, da palavramundo (FREIRE, 2003, p. 12). Pensar na palavamundo como eixo do trabalho de ensino nas escolas é projetar Revista Interinstitucional Artes de Educar. Rio de Janeiro, V. 4, N.1- pág. 204 - 219 - (jan. - abr. de 2018): “Questões contemporâneas sobre a Educação Especial na Perspectiva da Educação Inclusiva” - 
vínculos entre escola e realidade local; entre mundo escolar e mundo extraescolar; entre as experiências dos alunos e as experiências pensadas como currículo escolar. Neste sentido, mais uma vez, não há incompatibilidade em pensarmos diálogos entre Bakhtin e Paulo Freire. Ao contrário. Suas concepções de palavra se interpenetram, alimentando nossos sonhos de uma escola mais favorável a tomada da palavra de alunos e alunas no espaço institucional e na vida.

Larrosa (2002) diz que "a experiência é o que nos passa, o que nos acontece, o que nos toca [...] e ao passar-nos nos forma e nos transforma. Somente o sujeito da experiência está, portanto, aberto à sua própria transformação.” (LARROSA, 2002, p. 21 e 26). Entendemos a concepção de experiência defendida pelo autor como aquilo que ao nos acontecer, nos afeta, passa por dentro de nós, descortinando as certezas, mexendo com as ideias e os sistemas de valores já estabelecidos, provoca-nos a deixar o conformismo, sensibiliza-nos para um olhar mais sensível e crítico. Nesse sentido, entendemos a leitura como experiência, como produção de marcas que podem gerar (auto)formação e (trans)formação.

Por outro lado, Eliana Yunes e Glória Pondé (1989), dizem que literatura "pode ter manifestações diversas. E isso depende do ponto de vista e do sentido que a palavra tem para cada um.” (YUNES; PONDÉ, 1989, p. 38).

Muitas vezes a leitura na escola tem caráter obrigatório, acompanhados dos chamados "exercícios interpretativos". Em um deles, os alunos devem responder a uma ficha de leitura presente dentro dos livros. Composta por muitas perguntas a respeito da história lida, sua entrega preenchida era garantia de pontuação a ser adicionada à nota bimestral. No entanto, raramente representava uma garantia de engajamento leitor-texto. O foco não estava nas possíveis inferências e diálogos estabelecidos entre leitor - texto - autor. Com isso, o possível encantamento que o texto pudesse provocar, era trocado por trabalhos pré-estabelecidos

Kramer observa que:

A leitura na escola se fecha em leitura da escola, em que notas, provas de livros, fichas e apostilas com resumos das histórias ocupam o tempo e o espaço que, na concepção daqueles que preferem o gosto ao hábito, precisariam ser tempo e espaço de desfrutar o livro (KRAMER, 1999, p. 136).

A ideia de leitura, em Kramer, ajuda-nos a pensar sobre a vida, os seus sentidos e a relacionar as linhas do que é lido às vivências do mundo. A leitura concebida dessa maneira pode oportunizar naquele lê ou naquele que escreveu, aprendizados. Leitura que pode tornar-se experiência "quando o leitor se deixa tocar e realiza de maneira, primeiro, desconstrutora, depois constitutiva, seu enlace com a linguagem, com o que está antes e depois dela..." (YUNES, 2003, 
p.15). Nessa noção de leitura, o leitor não atribui ao texto um único sentido, mas permitindo-se enamorar com as palavras, envolve-se com o que está sendo lido/apreciado. A relação com a literatura, com a ficção traz aquele que lê a possibilidade de tornar a leitura como parte de si, entranhando-se nela, sendo dela pertencente e por ela pertencido, criando nesse espaço de interação uma pluralidade de significações.

Percebemos que muitas vezes as experiências de leitura escolares são transformadas em atos mecânicos de análises, cerceando o leitor e as infinitas possibilidades de desfrute do livro. Dentro desse contexto de discussão, encontramos em Abreu (2000):

se alterarmos o lugar de observação e visarmos às práticas de leitura escolares - nos colégios e universidades -, sobretudo quando o objeto é o texto literário, o quadro será bastante alterado. Aí, passaremos da diversidade à uniformidade. Uniformidade de textos, uniformidade dos modos de ler (ABREU, 2000, p. 124).

Para Nunes a paixão pelos livros pode ser percebida por "um estado de amor por um livro: aquela coisa aflita de estar sempre procurando um jeito de ficar sozinha com ele; só a gente e o livro.” (NUNES, 1988, p. 15). Ler nos afeta? Nos move? Nos constitui? O que é ler? - nos perguntamos mais uma vez. Freire afirma que: "a leitura da palavra não é apenas precedida pela leitura do mundo, mas por uma certa forma de "escrevê-lo" ou de "reescrevê-lo", quer dizer, de transformá-lo através de nossa prática consciente.” (FREIRE, 2003, p. 22).

Bakhtin (2011) aponta que os textos caracterizam o trabalho das ciências humanas, pois, o homem tem a especificidade de expressar-se sempre por meio de textos. Sem texto, não há o que investigar e o que construir como conhecimento.

Essa compreensão bakhtiniana distancia as ciências humanas das ciências exatas. Desse modo, investigamos com sujeitos e não com objeto de pesquisa. Encontramos perante vozes polifônicas e com elas buscamos estabelecer diálogos e não nos encontramos diante de textos esvaziados de sentidos ou de objetos mudos.

Consideramos por texto toda produção coerente que expressa-se no âmbito verbal ou nãoverbal, oral ou escrito. De acordo com Bakhtin, as ciências humanas não deveriam tentar compreender o homem em separado dos textos que produz.

O homem em sua especificidade humana sempre exprime a si mesmo (fala), isto é, cria texto (ainda que potencial). Onde o homem é estudado fora do texto e independentemente deste, já não se trata de ciências humanas (mas de anatomia, de fisiologia humanas etc.) (BAKHTIN, 2011, p. 312). 
Nessa direção, os estudos de Bakhtin inauguraram uma nova visão de linguagem, que passa a ser concebida como produto social e que existe por meio da constituição dialógica entre os sujeitos e a sociedade. Compreendida também como processo de interação, a linguagem produz e é produtora de ideologias, pois não acontece fora do sujeito e da história.

Então, enunciar não é simplesmente dizer alguma coisa, mas é considerar a alteridade, o outro, o contexto e o modo da interação verbal.

Toda enunciação, mesmo na forma imobilizada da escrita, é uma resposta a alguma coisa e é construída como tal. Não passa de um elo da cadeia dos atos de fala. Toda inscrição prolonga aquelas que a precederam, trava uma polêmica com elas, conta com as reações ativas da compreensão, antecipa-as (BAKHTIN, 2014, p.101).

Para Bakhtin (2014), na dinâmica enunciativa entre ouvinte e falante constrói-se a intersubjetividade humana, pois sendo a linguagem constituição social aquele que fala sempre se dirige a outro, que não é por completo um ouvinte passivo. Desse modo, o autor defende o caráter dialógico e ativo entre os sujeitos participantes do ato comunicativo e a critica a recepção passiva. Em Bakhtin, a linguagem tem dimensões dialógicas e ideológicas determinadas historicamente, por isso as palavras possuem intenções, sentidos.

A compreensão é, com base nos estudos bakhtinianos, ativa e dialógica já que:

As ciências exatas são uma forma monológica do saber: o intelecto contempla uma coisa e emite enunciado sobre ela. Aí só há um sujeito: o cognoscente (contemplador) e falante (enunciador). A ele só se contrapõe a coisa muda. Qualquer objeto do saber (incluindo o homem) pode ser percebido e conhecido como coisa. Mas o sujeito como tal não pode ser percebido e estudado como coisa porque, como sujeito e permanecendo sujeito, não pode tornar-se mudo; consequentemente, o conhecimento que se tem dele só pode ser dialógico (BAKHTIN, 2011, p. 400).

Narrativa é uma palavra que deriva do verbo "narrar" e cuja etimologia provém do latim narrare, remetendo ao ato de narrar, contar uma história. Esta ideia ganhou um ensaio inteiro na obra benjaminiana. Ao compartilhar narrativas orais, busca-se, dentre outras questões, renunciar a ilusão das aparências fugazes, das distâncias entre os indivíduos e do imediatismo produzido pelo mundo pós-moderno, que definha a arte de narrar e de intercambiar experiências.

Kramer (2010) nos propõe pensar que, "pela rememoração, na linguagem e na narrativa, resgata-se o poder de ser no presente, no passado e no futuro, tecendo a história, não mais como cronologia, mas como processo de recriação do significado" (KRAMER, 2010, p.155). As palavras da autora remeteram-me ao acento dado por Walter Benjamin no tocante à importância da rememoração, pois para este autor, ao rememorar, narrar o vivido o sujeito escapa do Revista Interinstitucional Artes de Educar. Rio de Janeiro, V. 4, N.1- pág. 204 - 219 - (jan. - abr. de 2018): “Questões contemporâneas sobre a Educação Especial na Perspectiva da Educação Inclusiva” - 
isolamento, opõe-se a crença de um passado imutável, podendo, por meio da linguagem, reconstituir sua história e a si mesmo. Por esse viés, rever o passado por meio da narrativa, pela rememoração, pode nos permitir olhar para o presente por perspectivas críticas e acenar a um futuro com possíveis mudanças.

\section{Considerações finais}

A palavra é uma espécie de uma ponte lançada entre mim e os outros. Se ela se apoia sobre mim numa extremidade, na outra apóia-se sobre o meu interlocutor (BAKHTIN, 2011, p. 294).

Lemos o tempo todo e de variadas formas, por isso toda experiência de leitura, por mais informal que possa parecer, pode abrir horizonte de possibilidades (BAKHTIN, 2011) para o indivíduo perceber-se no mundo e perceber o mundo. A contribuição, mediante o presente texto é, a partir dos diálogos tecidos, possibilitar ressignificações e reflexões, provocando movimentos que nos levem a considerar a linguagem como produção constituída nas interações e a leitura como processo dialógico, ligada à vida e as relações estabelecidas no/pelo texto. Nesse momento, deixamos um convite. O convite para continuarmos a discutir dialogicamente linguagem e leitura com olhares exotópicos (BAKHTIN, 2011) nos espaços/tempos pelos quais transitamos, pois, dessa maneira, estranharemos concepções lineares e engessadas que teimam em se legitimar, mas não favorecem um processo de ensino-aprendizagem.

Neste sentido, buscamos que nossas pesquisas provoquem ressonâncias e diálogos com e entre os protagonistas da escola. Para tanto, é necessário lembrar os escritos reflexivos de Garcia (2001) a respeito das investigações no meio acadêmico. Para a autora, faz-se necessário indagarmos se, de fato, o que pesquisamos e escrevemos contribui para melhorar a escola. Também indaga a autora se realmente conseguimos, por meio das pesquisas e escritas acadêmicas, estabelecer um espaço dialógico entre universidade-escola, trazendo contribuições mais efetivas para o desenvolvimento do trabalho pedagógico.

Concordando com Garcia, apontamos que quando universidade-escola busca dialogar, de forma horizontalizada, os processos que acontecem no cotidiano escolar podem se tornar visíveis, reconhecidos e legitimados como ações que possuem valor. A relação entre essas instituições educativas pode ainda oportunizar intercâmbios de conhecimentos e práticas, se constituindo como espaços formativos para ambos. Para tanto, devemos nos perguntar: como produzir pesquisas que não invisibilizem as vozes dos sujeitos? 
Garcia (2001) nos dá pistas aos dizer que "a dúvida, a incerteza, a insegurança, a consciência de nosso não saber é que nos convida a investigar e, investigando, podemos apreender algo que antes não sabíamos.” (GARCIA, 2001, p. 16). Nesse sentido, as interrogações, as indefinições, a curiosidade, assim como a vontade de querer saber mais, podem nos levar a buscar a ética da escuta na investigação.

Tentar compreender o modo como professores/as e estudantes se relacionam com a leitura, possibilita-nos refletir sobre a concepção de linguagem como prática social, de leitura como experiência e ato dialógico, e de literatura como expressão viva para repensar a vida, o lugar o indivíduo no mundo e o entrecruzamento do individual e do social no processo de auto-formação.

Freire (1997) defende a ideia da formação como processo permanente, pois, para ele, aquele que ensina, ao mesmo tempo, aprende, não existindo, portanto, ensinar sem aprender. Ainda segundo o autor, a "experiência docente, se bem percebida e bem vivida, vai deixando claro que ela requer uma formação permanente do ensinante. Esta perspectiva de formação se funda na análise crítica de sua prática.” (FREIRE, 1997, p.19). Vemos em Freire a defesa por uma formação docente que não seja fragmentária ou de maneira estanque, mas que aconteça de forma contínua e que provoque reflexões a respeito das práticas pedagógicas.

O enfoque freireano remete-nos aos escritos de Nóvoa, já que este defende que a "formação deve estimular uma perspectiva crítico-reflexiva" (NÓVOA, 1995, p. 25). Entendemos que para os dois autores a formação se constrói por meio de reflexão crítica, já que ambos apostam na ideia de formação como construção que provoque no sujeito movimentos que gerem dúvidas, questionamentos, incertezas e incômodos. Nóvoa (1995) ainda salienta que o acúmulo de cursos, conhecimentos ou técnicas não leva à formação. Desse modo, a defesa que o autor faz juntamente com a ideia de formação de professores aqui defendida podem também nos ajudar a problematizar os termos: formação inicial e formação continuada.

Kramer nos adverte que

Seria fundamental se pudéssemos generalizar e introduzir no processo de formação de professores a prática de ouvir o outro, o que exigiria que os próprios formadores aguçassem seus ouvidos, que as próprias secretarias e universidades aprendessem a escutar e reconhecer as trajetórias vividas. Isso, além de favorecer que levassem essas histórias em conta, as posicionaria num plano diverso, exatamente contrário, aliás, à idéia e à prática tão nefastas - ainda freqüentes - de colocar professoras e professores em ponto morto, fora de qualquer marcha (KRAMER, 1998, p. 32).

Diante disso, no tocante as ações formativas e/ou programas de formação docente que podem ser ofertados nos níveis federal, estadual e/ou municipal, e que se constituem como 
formação continuada de professores, cabe questionar em que medida tais formações dialogam e, consequentemente, contribuem com os processos formativos dos professores. Como essas ações têm oportunizado o compartilhar e a produção de conhecimentos e práticas?

Em que medida os professores continuam sendo reduzidos à condição de audiência passiva, em que o que ouvem distanciam-se de suas práticas, vidas, histórias e trajetórias de formação? Estariam essas vozes subjulgadas as palavras autoritárias (BAKHTIN, 2014b) que, constituídas sócio-historicamente, impositivas, com sentidos cristalizados e resistentes às relações dialógicas, ocupam os espaços e as ações formativas? Como diluir cristalizações nos espaços de formação continuada?

Os discursos autoritários e monológicos dificultam diálogos e experiências de (trans)formação, pois procuram impor-se, demarcando posições hierárquicas e buscando impedir a existência de questionamentos ou abertura para negociações de sentidos. Refletir sobre essas questões contribui para a formação de posturas críticas, de reflexividade e de práticas conscientes. Além disso, fortaleço a luta por ações e políticas formativas em que os sujeitos e suas vozes ocupem lugar de centralidade nas discussões.

Tanto a formação inicial quanto a formação continuada são termos precários. Portanto, ter um olhar atento para o modo como os termos tem sido pensados e propagados pode nos ajudar na construção do entendimento da formação como processo que se constitui e permanece ao longo do percurso de cada como tessituras sem meio ou fim.

Em Kramer (1998) temos ancorado nossos processos de compreensão a respeito da formação de professores, visto que a autora defende:

\footnotetext{
Uma perspectiva para a formação na qual não seja perdida a dimensão de experiências recontadas e ressignificadas; onde a formação seja praticada de maneira não-mecânica, impessoal, a-histórica e linear, mas como experiência compreendida e criticada, com possibilidade de transformação, como criação de linguagem humana, como produção de homens que se fazem sempre na história e que fazem a história (KRAMER, 1998, p. 28 e 29).
}

O viés defendido pela autora nos permite conceber a formação como experiência dialógica permanente. Isso significa que como acontecimento não linear, em um infindável processo, conhecimentos podem ser revisitados, incluídos e dialogados. Nesse sentido, Bakhtin (2011) também nos ajuda, pois leva-nos a entender que os indivíduos, de forma mútua, se constituem, sendo ainda marcados por suas histórias, concepções e experiências vividas.

Quando a formação de professores é concebida como permanente, o indivíduo passa ser compreendido como sujeito em constante processo de construção de conhecimento. Essa Revista Interinstitucional Artes de Educar. Rio de Janeiro, V. 4, N.1 - pág. 204 - 219 - (jan. - abr. de 2018): “Questões contemporâneas sobre a Educação Especial na Perspectiva da Educação Inclusiva” - 
concepção pode favorecer que o sujeito pense reflexivamente a respeito dos processos de formação vividos como (auto)formativo. Além disso, a ideia da formação docente como contínua pode contrapor à teoria de formação que defende o professor como mero espectador, que necessite esquecer ou substituir tudo o que já sabe. Por esse viés, encontramos a formação docente sendo entendida como possibilidade para "reciclar", "atualizar", "formatar", "capacitar". Kramer e Souza (1996) alertam que

A idéia de capacitar parte do princípio de que alguém é incapaz. Assim como a ideia de reciclar parte do princípio de que alguém vai jogar fora o velho e absorver o novo. Essas propostas geram no professor reações de descrédito, de cansaço, de aversão (KRAMER e SOUZA, 1996, p. 156).

Para Kramer e Souza (1996) trazem um discurso em que as noções apresentadas podem desprivilegiar professores e professoras, além de colocá-los numa posição de passividade. Além disso, quando os sentidos trazidos na citação permeiam a formação de professores, esta, por vezes, é entendida como espaço/tempo que parte de um marco zero de conhecimento, como se os docentes fossem "tabulas rasas", ou seres descartáveis que não trazem em si contribuições e que as propostas da formação naquele momento se tornam as únicas consideradas legítimas.

Assim, vamos tentando construir um olhar que nos ajude a superar a "curiosidade ingênua que caracteriza a leitura pouco rigorosa do mundo" para uma "curiosidade exigente" (FREIRE, 1996, p. 11) que nos permita perceber e tencionar a formação de professores e os espaços/tempos formativos.

Por fim, retornando ao tema da leitura, podemos tomar de empréstimo o dito por Fernando Pessoa, e pensar que o valor da literatura em geral, e da leitura em especial, é a "confissão de que a vida não basta". E se a vida não basta, há que ser acompanhada da leitura e da escrita para que transborde de alegria.

Esperamos que o leitor entre no diálogo com este texto, acrescentando suas palavras às que se encontram escritas, construindo elos enunciativos e reflexivos.

\section{Referências}

ABREU, M. As variadas formas de ler. In: PAIVA, A. (Org.). No fim do século: a diversidadeo jogo do livro infantil e juvenil. Belo Horizonte: Autêntica, 2000. p. 121-134.

ALVES, Nilda. Cultura e cotidiano escolar. Revista Brasileira de Educação, São Paulo, n. 23, p. 62-74, mai./ago. 2003. 
BAKHTIN, M. M. Estética da criação verbal. São Paulo: Martins Fontes, 2011. . Marxismo e Filosofia da Linguagem. São Paulo: Hucitec, 2014.

. Questões de Literatura e de estética: a teoria do romance. São Paulo: Hucitec, 2014b. . Problemas da poética de Dostoiévski. Rio de Janeiro: Forense Universitária, 2008.

BENJAMIN, W. Magia e técnica, arte e política. São Paulo: Brasiliense, 1994. (Obras Escolhidas, v.1).

COUTINHO, Eduardo. O cinema documentário e a escuta sensivel da auteridade. In ANTONACCI, Maria Antonieta e PERELMUTTER, Daisy (orgs). Projeto História - ética e história oral. S. Paulo: PUC/SP, abr./97, (15): 165 - 191.

FREIRE, P. Professora sim, tia não: cartas a quem ousa ensinar. São Paulo: Olho d'água, 1997.

KRAMER, S. Alfabetização, leitura e escrita: formação de professores em curso. São Paulo: Ática, 2010.

. Leitura e escrita de professores em suas histórias de vida e formação. Cadernos de Pesquisa, n.106, p. 129-157, mar. 1999. Disponível em:

<http://www.scielo.br/pdf/cp/n106/n106a06.pdf>. Acesso em: 18 dez. 2016.

.Leitura e escrita de professores: da prática de pesquisa à prática de formação. Revista Brasileira de Educação, Rio de Janeiro, n. 7, p. 19-41, jan/fev/mar/abr. 1998. Disponível em: <http://anped.org.br/rbe/rbedigital/RBDE07/RBDE07_04_SONIA_KRAMER.pdf.> Acesso em: 09 abr. 2015.

; SOUZA, S J. (Org.). Histórias de professores: leitura, escrita e pesquisa em educação. São Paulo: Ática, 1996.

LARROSA, J. Notas sobre a experiência e o saber de experiência. Revista Brasileira de Educação, Rio de Janeiro, n. 19, p. 20-28, jan./fev./mar./abr. 2002.

MORAIS, Jacqueline de F. dos Santos. Histórias e narrativas na educação infantil. In: GARCIA, Regina L. (org). Crianças, essas conhecidas tão desconhecidas. Rio de Janeiro: DP\&A, 2002, p.81-101.

Nóvoa, A. Formação de professores e profissão docente. In: formação. Portugal: Publicações Dom Quixote, 1995. p. 15-33. . Os professores e a sua

NUNES, L. B. Livro: um encontro com Lygia Bojunga Nunes. Rio de Janeiro: Agir, 1988.

FERREIRA, A. B. DE H. Novo Dicionário Aurélio da Língua Portuguesa. São Paulo: Nova Fronteira, 2 ed. Revista e aumentada, 1986. 
FREIRE, P. A importância do ato de ler. In: FREIRE, P. A importância do ato de ler em três artigos que se completam. São Paulo: Cortez, 2003, p. 11-24.

YUNES, E. ; PONDÉ, G. Leitura e leituras da literatura infantil: Por onde começar? São Paulo: FTD, 1989.

YUNES, E. Leitura como experiência. In: ; OSWALD, M. L. (Org.) A experiência da leitura. São Paulo: Loyola, 2003. p. 7-15.

\footnotetext{
${ }^{\text {i }}$ Professora Adjunta da Faculdade de Formação de Professores e do Programa de Pós-Graduação em Educação da Universidade do Estado do Rio de Janeiro. É Jovem Cientista da FAPERJ.

ii Mestra em Educação pela Faculdade de Formação de Professores da Universidade do Estado do Rio de Janeiro (FFP/UERJ). Professora do Ensino Fundamental na Rede Municipal de Educação de Niterói - RJ e professora de Língua Portuguesa da Secretaria de Educação do Estado do Rio de Janeiro.
} 